\title{
As concepções de interatividade nos ambientes virtuais de aprendizagem
}

\author{
Maria das Graças Barros \\ Ana Beatriz Gomes Carvalho
}

SOUSA, RP., MIOTA, FMCSC., and CARVALHO, ABG., orgs. Tecnologias digitais na educação [online]. Campina Grande: EDUEPB, 2011. 276 p. ISBN 978-85-7879-065-3. Available from SciELO Books $<$ http://books.scielo.org $>$.

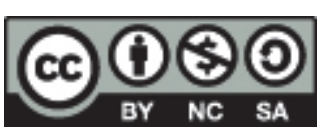

All the contents of this work, except where otherwise noted, is licensed under a Creative Commons Attribution-Non Commercial-ShareAlike 3.0 Unported.

Todo o conteúdo deste trabalho, exceto quando houver ressalva, é publicado sob a licença Creative Commons Atribuição Uso Não Comercial - Partilha nos Mesmos Termos 3.0 Não adaptada.

Todo el contenido de esta obra, excepto donde se indique lo contrario, está bajo licencia de la licencia Creative Commons Reconocimento-NoComercial-CompartirIgual 3.0 Unported. 


\title{
As concepções de interatividade nos ambientes virtuais de aprendizagem
}

\author{
Maria das Graças Barros \\ UEPB - Campina Grande, Paraíba \\ galbarros2@hotmail.com \\ Ana Beatriz Gomes Carvalho \\ UEPB- Campina Grande, Paraíba \\ anabeatrizuepb@gmail.com
}

\section{Introdução}

Sabemos que o avanço da tecnologia tem influenciado a economia mundial, e por conta disso, as relações de mercado e pessoais já não são mais as mesmas. Hoje, as relações giram em torno do consumo, da competitividade e da competência. Uma nova ordem se levantou: da globalização ou mundiatização, da interconectividade, da informação. A nova era da Sociedade da Informação exige maior rapidez e demanda quantidade de informação, o que nos leva a elaborar outros olhares e a eleger novos interesses. Portanto, em face dessas mudanças as instituições também tentam se adequar para atender às exigências atuais. 
É nessa perspectiva, que pensamos a educação. Educação de qualidade e inclusiva, a que deva preparar o indivíduo para interagir com o meio com maturidade, autonomia e criticidade, ou seja, aquela que prepare o indivíduo para compreender e intervir em prol de uma sociedade mais humana, sem se deixar excluir, ou mesmo, se deixar levar pela enxurrada de informações que as mídias produzem.

A Educação a Distância (EAD) é uma modalidade que tem ao longo da história se transformado e com isso se colocado como uma alternativa para os dias atuais. Se no início, ela se prestava apenas a atender aos interesses econômicos vigentes na sociedade, de tal forma que o ensino era meramente unilateral (ensino por correspondência), e focado na tecnologia utilizada para tal veiculação (correios, rádio), vencer a barreira da distância e qualificar massivamente a população eram seus objetivos. Hoje, porém, a educação a distância amplia-se juntamente com as novas tecnologias e agrega novos valores pedagógicos e, por isso, pode constituir-se, como já foi dito, numa alternativa para inclusão social.

Um dos fatos que justifica o nosso interesse por Educação a Distância é acreditar que esta modalidade apresenta características que podem ajudar a superar e romper algumas formas de exclusão. Uma delas é que a EAD surge rompendo a barreira do tempo e do espaço. A pessoa conectada em uma rede, por intermédio da internet, pode receber informações, pesquisar e produzir conhecimentos, atendendo a um dos princípios do ensino a distância que é a flexibilidade, que segundo Belloni (2006) possui diferentes acepções que vão desde a flexibilização do acesso, flexibilização do ensino, da aprendizagem e até a da oferta.

Tendo em vista a Educação a Distância utilizar-se de ferramentas tecnológicas para a realização do processo de aprendizagem, compreender esse papel na mediação pedagógica, constitui-se num debate que se amplia para o questionamento: até que ponto as ferramentas tecnológicas, promotoras de aprendizagem colaborativa, 
oportunizam aos alunos de Administração a Distância a ressignificação do conhecimento, ou seja, oportunizam uma relação de construção de significados.

Portanto, este trabalho tem por objetivo geral analisar o Ambiente virtual de aprendizagem enquanto plataformas integradoras de ferramentas tecnológicas e pedagógicas, propiciadora de aprendizagem, dando destaque às interfaces tecnológicas interativas.

Como objetivos específicos, pretendemos investigar as ferramentas pedagógicas disponíveis no Ambiente Virtual de Aprendizagem - Moodle; analisar os instrumentos das NTIC que são potencializadores e quais são os inibidores, a partir do conceito de interatividade e identificar possíveis dificuldades dos alunos do curso de Administração a distância da UEPB no uso das ferramentas de aprendizagem colaborativa e ao mesmo tempo buscar indicadores que apontem para a superação dos obstáculos e disseminação das soluções.

\section{Educação a distância e as Novas Tecnologias de Informação e Comunicação}

Educação, segundo o dicionário de Aurélio, diz respeito "ao processo de desenvolvimento da capacidade física, intelectual e moral da criança e do ser humano em geral, visando à sua melhor integração individual e social" (FERREIRA, 1986, p. 499). Todavia, para que seja efetivada a integração entre pessoas, e para a promoção intelectual e física do ser humano é necessário que técnicas sejam criadas para a realização dos eventos que promovam a sua ascensão.

Para a educação assistemática, os conhecimentos são passados oralmente ou escrito de pessoas para pessoas, de geração para geração. Já os conhecimentos sistematizados são transmitidos em um ambiente físico fechado, a partir de sugestão de conteúdos 
que imaginamos atenderem às necessidades daquela faixa etária. Nestes casos, o uso de tecnologia tem sido incorporado para que as ações educativas sejam concretizadas. Em um primeiro momento, fez-se necessário a invenção dos livros, jornais, revistas, a partir do advento da escrita. Mais adiante, o rádio, o telefone, a televisão se transformaram em instrumentos tecnológicos que viabilizaram uma educação que ultrapassaram as paredes de uma escola tradicional. A educação começa a ser oferecida para além do espaço e do tempo com a ajuda da tecnologia. Hoje, a educação a distância, com a ajuda das NTICs, permite, através da internet, que as pessoas se comuniquem sincrônica ou assincronicamente, formando uma rede de comunicação e aprendizagem colaborativa.

Nesse sentido, a Educação a Distância é considerada uma alternativa para a Educação, justificada sua implantação no Brasil pelo alto índice de analfabetismo, a baixa escolaridade da população, a qualificação profissional deficitária e a sua grande extensão territorial do país. Para Moran (2002) a EAD é o "processo de ensino-aprendizagem, mediado por tecnologias, onde professores e alunos estão separados espacial e/ou temporalmente". Esse conceito nos remete ao contexto sócio-histórico que demandou a possibilidade de oferecer educação a pessoas que estavam distantes dos grandes centros acadêmicos e/ou não tinham disponibilidade de freqüentar diariamente uma escola. Nessas condições, as novas tecnologias chegam para suplantar o problema da distância e atender, portanto, às necessidades dessas pessoas.

Entretanto, essa modalidade de ensino almeja e concretiza mudanças que vão de uma educação baseada na transmissão da informação, na instrução, para a criação de ambientes de aprendizagem, onde o aluno realiza atividades e constrói o seu conhecimento. Com as NTICs, uma nova prática de Educação a Distância ocupa lugar de destaque na pedagogia, uma vez que possibilita flexibilidade do tempo, quebra as barreiras espaciais, emite e recebe instantaneamente materiais, e, sobretudo, potencializa, através da 
interatividade e interação, a comunicação entre pessoas e a construção de conhecimento. Segundo Silva (2003) com o avanço da tecnologia teremos tanto a massificação de boa parte dos cursos superiores como novas formas de aprender continuamente.

Essa é a perspectiva da Educação a Distância, que junto com o avanço da tecnologia, permite-nos prognósticos que vão além do que é real hoje. No entanto, ela é uma realidade que se impõe perante a sociedade como uma alternativa que atuará justamente onde o ensino presencial não consegue atender, ou ainda, atuará como um elemento a mais no ensino presencial, o qual pode ser beneficiado pelas interfaces que permitem a pesquisa e a construção coletiva da aprendizagem.

De acordo com Primo (2000 apud FERREIRA; BIANCHETTI, 2002, p. 260) "[...] as novas tecnologias da informação e da comunicação vêm contribuindo para a modificação da forma de as pessoas se relacionarem e de construírem conhecimentos, pois elas proporcionam múltiplas disposições à intervenção do interagente". $\mathrm{O}$ fato de as pessoas poderem expor seus trabalhos na internet $\mathrm{e}$ receber comentários sobre eles; de produzir textos colaborativamente, de participar de comunidades virtuais que oportunizam participação por temas de interesse, de discussões virtuais, de comunicação instantânea, de espaços para divulgação individual e coletiva, corroboram com as idéias do autor supracitado, e permite acrescentar que as NTICs surgem como suporte para a EAD apresentar uma proposta de integração, potencializada por meio de diversos dispositivos disponíveis, atualmente.

Para tanto, temos que considerar o fato de vivermos em um país de muita desigualdade social, que tem um número elevado da população sem acesso a computadores e muito menos à internet. Políticas públicas têm sido realizadas nesse sentido. O governo tem enviado equipamentos para as escolas, mas ainda falta mão de obra qualificada para técnica computacional e, sobretudo, professores preparados pedagogicamente também para o uso da tecnologia na 
educação. A maioria dos professores não faz parte dessa geração tecnológica, e, por isso, têm muita resistência para compreender essas inovações. Mas, é o professor que deve exercer a função de orientar os alunos quanto ao uso e caminhos a serem trilhados com as novas tecnologias.

Portanto, é importante compreender que os desafios da EAD são equivalentes aos desafios do sistema educacional em sua totalidade, o que implica em analisar a educação que pretendemos realizar, para quem dirigimos, com quem será desenvolvida, com o uso de que tecnologias e que abordagens mais adequadas devem ser exploradas para acelerar o processo de inclusão social da população brasileira.

\section{Ambiente Virtual de Aprendizagem: 0 Moodle}

Para a promoção de cursos a distância, ambientes virtuais estruturados são desenvolvidos com o objetivo de promover a aprendizagem. São espaços eletrônicos construídos para permitir a veiculação e interação de conhecimentos e usuários, Esses ambientes são chamados de Sistemas de Gerenciamento de Aprendizagem (do inglês: Learning Management Systems - LMS). São softwares projetados para atuarem como salas de aula virtuais e têm como características o gerenciamento de integrantes, relatório de acesso e atividades, promoção da interação entre os participantes, publicação de conteúdos.

Os LMS são Ambientes Virtuais de Aprendizagem (AVA), que diferentemente de outros, oferecerem características de controle e gerenciamento inexistentes em outras interfaces da web. Os ambientes de aprendizagem se caracterizam e se diferenciam de outros ambientes da web porque eles têm uma dinâmica própria para atender ao fazer pedagógico, o qual é orientado no sentido de que se estabelecem metas para o aluno atingir. Outro diferencial é o oferecimento de feedback. O feedback é fundamental para que os 
alunos possam avaliar se estão atingindo os objetivos estabelecidos para o curso. Objetivos orientados a feedback são um dos aspectos críticos de um ambiente de aprendizagem, pois, se o aluno não recebe comentário sobre as atividades que ele desenvolveu em um curso ele não tem como saber se está ou não atingindo os objetivos estabelecidos.

Nos AVA's, os recursos que dão suporte à educação a distância são os mesmos da internet: correio, fórum, chat, conferência, banco de recurso. $\mathrm{O}$ gerenciamento desses ambientes engloba diferentes aspectos, dos quais destacamos a gestão das estratégias de comunicação e mobilização dos participantes, a gestão da participação dos alunos por meio de registro das produções, interações e caminhos percorridos, a gestão de apoio e orientação dos formadores aos alunos e a gestão da avaliação.

Apresentamos o Moodle, neste trabalho, por ser o ambiente de aprendizagem, utilizado na maioria das universidades públicas, inclusive pela Universidade Estadual da Paraíba para viabilizar seus cursos a distância, objeto de nosso estudo.

Pelo fato de ser um software livre, gratuito e aberto, o Moodle pode ser carregado, utilizado, modificado e distribuído. Ele é um projeto de desenvolvimento contínuo, por isso, podemos receber atualizações constantes, tendo também os próprios usuários como seus construtores. Por propor uma aprendizagem colaborativa on-line, ele é considerado um ambiente baseado numa proposta sócio-construtivista. Segundo o seu criador Martin Dougiamas, que lidera o projeto até hoje, "não se trata a aprendizagem como atividade social, mas focaliza a atenção da aprendizagem que acontece enquanto construímos ativamente artefatos (como textos, por exemplo), para que outros vejam ou utilizem" (MUZINATTI, 2005).

Sendo assim, o Moodle é um ambiente que permite a adequação das necessidades das instituições e dos usuários, e, enquanto ambiente virtual de aprendizagem, foi desenvolvido levando em 
consideração que a aprendizagem acontece, através da colaboração do conhecimento. Percebemos aqui na filosofia do desenvolvimento do Moodle uma clara expressão das intenções de promover a colaboração e cooperação do outro para com o outro, buscando desenvolver uma cultura baseada em conhecimentos compartilhados entre o grupo.

O fato de o Moodle ser um ambiente de aprendizagem que possibilita o feedback, a própria construção do ambiente e a construção do conhecimento compartilhado conduz que se adote uma concepção social para a compreensão de sua dinâmica de aprendizagem. Pulino Filho (2005, p. 6) comenta a esse respeito que o "termo processo social sugere que a aprendizagem é alguma coisa que se faz em grupos. Deste ponto de vista, aprendizagem é um processo de negociação de significados em uma cultura de símbolos e artefatos compartilhados"

Para o desenvolvimento das atividades são utilizados recursos que reforçam os princípios sóciointeracionistas pelo fato de oportunizarem a comunicação e a intervenção do usuário durante o processo. Esses recursos são disponibilizados no ambiente e oportunizam a interação dos alunos com os conteúdos e com colegas e professores.

Essas ferramentas são consideradas de informação e comunicação. No caso das interfaces de comunicação destacam-se as ferramentas de interatividade síncronas e as assíncronas. As ferramentas de comunicação síncronas são as que permitem a participação de alunos e professores em eventos marcados, com horários específicos, via internet, a exemplo dos chats. Para esse tipo de interatividade, a comunicação em tempo real, possibilita aos envolvidos uma sensação de grupo, de comunidade, o que pode ser determinante para a continuidade do curso, uma vez que preserva a motivação, a interação em tempo real, o retorno e a crítica imediata, encontros regulares, etc. Já as ferramentas de comunicação assíncronas como o Fórum, o Diário, o diálogo, a lição, entre 
outros, são consideradas como revolucionárias pelo fato de possibilitar que o usuário faça sua intervenção de forma mais organizada, uma vez que ele terá tempo para sistematizar sua opinião, comentário, respostas, etc.

Cada uma dessas ferramentas tem uma função definida no ambiente e com possibilidades limitadas e cabe ao professor selecioná-las, conforme os objetivos de seu curso. Todavia se acrescenta que como o Moodle é um ambiente de construção pública e livre, ele pode ser alterado e novas ferramentas podem surgir e serem agregadas a já existentes.

As ferramentas mais comuns no ambiente Moodle são as seguintes: arquivo de Materiais, Lição, Fórum, Tarefa, Questionário, Chat, SCORM, Glossário, Pesquisa de Opinião, wiki, Pesquisa de Avaliação, Diário, Diálogo

O emprego das NTICs na educação possibilita a criação de ambientes novos com estruturas flexíveis, abertas, integrando várias mídias e possibilitando a interação entre os participantes do processo. Mas o uso da tecnologia reforça a existência de um projeto educativo com definição de perfil de alunos, objetivos, parâmetros pedagógicos, conteúdo e avaliação dos conteúdos que serão ministrados, além de ajustes no decorrer do processo ensinoaprendizagem. E o grau de interatividade presente nelas vai, em muito, depender da mediação pedagógica que subjaz ao processo de ensino e aprendizagem a que se propõe o curso, o professor.

\section{Na interatividade pela interação}

O ensino a distância on-line tem sido divulgado como uma alternativa que se configura hoje pela inserção das novas tecnologias de informação e comunicação e junto com elas a idéia da interatividade. Conceito que vem sendo muito discutido, pelo fato de amparar valores e concepções que têm variado no tempo e na história. 
Silva (2006) tem contribuído bastante com o debate nacional sobre interatividade, quando apresenta algumas posições de autores, sobretudo, quando ele apresenta o debate que se travou na França em meados dos anos 80 sobre o termo interatividade. Embates que reconheciam a complexidade e a importância do termo. Ele aponta três reações freqüentes ao termo "interatividade": a primeira como oportunista, ou seja, como modismo, nome novo para coisas velhas. A segunda como estratégia de marketing para expansão do mercado e a terceira como uma estratégia de dominação da técnica, que promove a regressão do homem à condição de máquina.

Mas para Silva, (2006) a terminologia interatividade surge para atender a uma nova modalidade comunicacional, a interativa, que se caracteriza pelo modo dialógico com que os usuários interagem uns com os outros. A interatividade é vista como um fenômeno que emerge da Sociedade da Informação, que para Assmann (2005, p. 16) "é a sociedade que está atualmente a constituir-se, na qual são amplamente utilizadas tecnologias de armazenamento e transmissão de dados e informação de baixo custo”. Assmann (2006) também acredita que apenas a disponibilização da informação não caracteriza a Sociedade da Informação, mas o diferencial e o que é mais importante "é desencadeamento de um vasto e continuado processo de aprendizagem” (ASSMANN, 2006, p.16).

Assim, dizemos que as novas tecnologias que permitem a interatividade também promovem uma nova relação do aluno com o conhecimento, com outros alunos e com o professor, a partir do momento, em que se propõe um ensino que considera como prioridade as formas de aprendizagens e, conseqüentemente, os aprendentes. A possibilidade de interagir, através das ferramentas tecnológicas, implica rever todos os papéis dos envolvidos no processo ensino e aprendizagem e como também a metodologia utilizada para a promoção dessa aprendizagem. 
O papel do professor se amplia. Ele deve promover, por força de uma intervenção pedagógica, a autonomia do aluno, no sentido de ajudá-lo a reelaborar o conhecimento existente. Ao professor cabe o papel de promotor-interventor. Silva (2006) acrescenta que o professor na perspectiva da interatividade deixa de ser o contador de histórias, conselheiro, parceiro ou mesmo facilitador e passa a ser um sistematizador de experiências.

Os alunos, desta forma, deixam de aprender passivamente, como acontece com o ensino instrucionista, em que a máquina ou o professor transmitem ou repassam as informações, e passam a exigir mais, tanto dos proponentes quanto de si mesmos, exigindo liberdade e autonomia. Autonomia que, para Morin (1995 apud ASSMANN, 2005), significa o estabelecimento das relações que o aluno construir com o mundo exterior e os outros.

Se por interação entendemos ação recíproca que se estabelece entre pessoas ou coisas, Primo e Cassol (1999, p.67) afirmam que "interação são as relações e influências mútuas entre dois ou mais fatores, de modo que cada um altera o outro e a si próprio, bem como a relação existente entre eles".

Na visão sóciointeracionista, o homem constitui-se como tal, por meio de suas interações sociais, portanto, ele é visto como alguém que transforma e é transformado nas relações produzidas em uma determinada cultura. $\mathrm{Na}$ interação com o outro e com o meio, o indivíduo se deparará com situações conflitantes, que exigirão que ele encontre as possíveis soluções, o que possibilitará a aprendizagem e conseqüentemente, o seu desenvolvimento intelectual.

No contexto de $\mathrm{EAD}$, o favorecimento da interação é marcada pela ação dialógica entre o sujeito e a técnica. Para Hodgson (2001apud VAN DER LINDEN, 2005, p. 63) "o termo interação ao ser incorporado pela internet, transmuta-se em interatividade, traduzindo-se num tipo singular de interação". 
Com as tecnologias disponibilizadas, a educação a distância oportuniza, portanto, maior interatividade entre professor e aluno, alunos e alunos, todos e máquina, ampliando, renovando e construindo conhecimentos porque as novas tecnologias comunicacionais permitem ampla liberdade para o usuário fazer as conexões que lhe forem convenientes, de forma a atualizarem-se e de produzirem as intervenções que mais lhe convierem.

Assim, temos um movimento entre interação e interatividade que vai além do humano e máquina, uma vez que a interação é relação necessária entre sujeito e objeto para a aquisição do conhecimento e interatividade condição sine qua non para a acessibilidade à comunicação em rede, conseqüentemente, essas relações estão tão imbricadas, que uma não se diz sem a outra em EaD.

Investir na interatividade significa investir em novos caminhos, em novos desafios, que serão superados no fazer coletivo, na superação individual. A educação a distância, que oportuniza instrumentos tecnológicos para aproximar pessoas, para garantir a reelaboração do conhecimento e o acesso ao conhecimento científico, tem como objetivo preparar o indivíduo para a vida, para intervir no mundo de forma madura e autônoma, autonomia no sentido de compreensão, de poder de decisão e de escolha e ainda de construção. Que esse indivíduo compreenda que ele faz parte de uma sociedade, que se transforma e que ele, enquanto agente dela, tem que estar preparado para acompanhar e participar dessas transformações.

Assim sendo, a proposta de Educação a Distância que pretende a promoção do ensino, ensejando que o aluno aprenda com as novas tecnologias interativas, pretende sim a sua promoção social, por meio da interação pela interatividade. O conceito de interatividade, como mais um recurso para a intervenção do aluno no processo de aprendizagem, de forma que a sua participação possa influenciar outros e a si mesmo. Todavia, caberá ao professor pesquisar e propor situações e/ou atividades que levem em consideração os 
recursos que a tecnologia oferece para ampliar o mundo do aluno, numa perspectiva de reconstrução e de aprendizagem colaborativa. Silva (2006) acrescenta que as novas tecnologias interativas permitem a participação, a intervenção, a bidirecionalidade e a multiplicidade de conexões.

\section{A influência de Vygotsky para uma teoria de aprendizagem em EAD}

O processo de aprendizagem pelo qual o sujeito passa quando está diante de um objeto de conhecimento pode ser observado sob várias concepções, todavia, quando se entende que a aprendizagem é um processo ativo que conduz a transformações no homem, o olhar se desvia para uma orientação em que o processo se estabelece pelas relações, sobretudo, pelas relações sociais. Esta idéia nos remete a Vygotsky (1998), para quem a questão da relação entre os processos de desenvolvimento e de aprendizagem é central. Mas é o aprendizado que possibilita o despertar de processos internos de desenvolvimento, ou seja, o aprendizado precede o desenvolvimento. Quanto mais se oferece à criança mais chance ela tem para se desenvolver.

Com base nos estudos de Vygotsky (1998), apresentamos alguns conceitos que são fundamentais para que se compreenda a formulação da concepção sóciointeracionista e sua influência para a educação, em especial, para a educação a distância. A teoria da dupla formação das funções psicológicas superiores, a internalização, a mediação e a zona de desenvolvimento proximal.

As funções psicológicas superiores, que compreendem a consciência, a intenção e o planejamento, dizem respeito ao estabelecimento das relações sociais que aparecem, primeiramente sob a forma de processos intermentais, ou interpessoais, que significa que o conhecimento se dá entre as pessoas, num contexto externo para depois passar para processos intramentais ou individuais, o processo é, neste caso, interno. 
Portanto, é do social para o individual que o homem se constitui, de fora para dentro, o que significa dizer que o homem tem características próprias, mas necessita da experiência do outro para viver melhor. Já para o entendimento do processo de internalização compreende-se que a aprendizagem se dá mediante a reconstrução interna de uma operação externa, ou seja, quando o sujeito consegue reconstruir um conhecimento existente, resultado dos processos interpsicológico e intrapsicológico.

Todos esses processos cognitivos têm como base a mediação: enquanto sujeito do conhecimento o homem não tem acesso direto aos objetos, mas acesso mediado, através de recortes do real, operados pelos sistemas simbólicos de que dispõe, portanto enfatiza a construção do conhecimento como uma interação mediada por várias relações.

Por último, destacamos o conceito da zona de desenvolvimento proximal, como um dos níveis de desenvolvimento pelo qual a criança passa no processo de aquisição do conhecimento e que serve para indicar o nível de desenvolvimento em que se deve intervir para que a criança avance e aprenda o conhecimento em potencial.

Segundo Oliveira (1999, p. 59), para Vygotsky (1998), a capacidade de a criança realizar tarefas sozinha representa o nível de desenvolvimento real, que representa resultado de processos maduros. Neste nível, a criança já tem consolidado o conhecimento. Já o nível de desenvolvimento potencial, significa o conhecimento que está por vir, aquele que pode ser internalizado, e que foi detectado na zona de desenvolvimento proximal. Representa o conhecimento que pode ser alcançado com a ajuda do outro, de um colega, pais, professores, ou mesmo, por qualquer objeto sócio-cultural. Por isso, as potencialidades do indivíduo devem ser levadas em conta durante o processo de ensino-aprendizagem, como forma ativar os seus esquemas cognitivos ou comportamentais nas variadas situações de aprendizagem. 
Para Vygotsky (1998), a interação social exerce um papel fundamental no desenvolvimento cognitivo, uma vez que ele parte do princípio de que o desenvolvimento das formas superiores do comportamento (pensar, relacionar, analisar, comparar, etc) pressupõe o aprendizado, que essencialmente cria a zona de desenvolvimento proximal, ou seja, o aprendizado desperta vários processos internos de desenvolvimento, que são capazes de operar quando o sujeito interage com outros em seu ambiente e quando em cooperação com seus companheiros. O aprendizado adequadamente organizado resulta em desenvolvimento mental e põe em movimento vários processos de desenvolvimento que, de outra forma, seriam impossíveis de acontecer.

Em termos gerais, Vygotsky (1998) trouxe para a educação reflexões que permitem pensar a prática pedagógica sob ótica da aprendizagem. Para ele a concepção de ensino e aprendizagem inclui, por um lado, a idéia de que quem ensina e quem aprende não se refere necessariamente a situações em que haja um educador fisicamente presente e que a presença do outro social pode se manifestar por meio de objetos, do próprio ambiente, dos significados que rodeia o mundo cultural do indivíduo. (OLIVEIRA, 2003)

Neste contexto sóciointeracionista, vislumbramos a Educação a Distância como uma modalidade que se utiliza de dinâmicas participativas de cooperação e de comunicação, regras flexíveis, do desenvolvimento da criatividade e da individualidade. O aluno é quem constrói seu próprio conhecimento, sendo auxiliado pelo Tutor/Professor, que o ajuda, instiga-o a avançar e a aguçar a curiosidade. Acompanha o processo de construção do conhecimento do aluno, sempre atento ao fato de que cada ser humano tem sua forma peculiar de aprendizagem, exercendo, assim, papel de mediador da aprendizagem.

Esta teoria pode ser aplicada em EAD, pois respeita o ritmo do aluno, considerando-o como um ser único, sendo ele, aluno, o sujeito da aprendizagem. 
O fato de o ensino e a aprendizagem serem veiculados e processados por uma máquina, não minimiza, como já foi dito, o papel do professor, que nesta propositura tem a função de mediador e, portanto, será responsável pelo material didático postado no ambiente virtual. De acordo com a concepção sóciointeracionista, o material deverá ser atrativo, favorecer o questionamento, a reflexão e, conseqüentemente, a reelaboração do conhecimento. Também, deverão prezar pela interação entre os colegas e, por conseguinte, pela socialização do conhecimento. A aprendizagem é, pois, vista como atividade de elaboração conceitual em um ambiente caracterizado pela interação.

As atividades propostas para a educação a distância, portanto, devem considerar a questão da capacidade individual do aluno e por isso, oferecer atividades que venham a contribuir com o seu avanço intelectual. Para tanto, deve-se propor atividades que permitam o feedback, a devolutiva com as orientações necessárias, de forma que o aluno seja obrigado e motivado a repensar o conhecimento existente. A proposta deve ser desafiadora e problematizadora. $\mathrm{O}$ professor, enquanto mediador, deve avaliar o aluno, a partir de sua capacidade de entendimento e de sua produção oral e escrita. Os conteúdos propostos devem considerar o contexto sócio-históricocultura, no qual estão inseridos os alunos, e os objetivos do curso.

Entendemos, pois, que no dizer de Vygotsky (1998), como a aprendizagem impulsiona o desenvolvimento, a escola tem um papel essencial na construção do ser psicológico e racional. A escola deve dirigir o ensino não para etapas intelectuais já alcançadas, mas sim para estágios de desenvolvimento ainda não incorporados pelos alunos, funcionando como um incentivador de novas conquistas psicológicas. Assim, a escola tem ou deveria ter como ponto de partida o nível de desenvolvimento real da criança (em relação ao conteúdo) e como ponto de chegada os objetivos da aula que devem ser alcançados, ou seja, chegarem ao potencial da criança. "Aqui o professor tem o papel explícito de interferir na zona de 
desenvolvimento proximal dos alunos, provocando avanços que não ocorreriam espontaneamente" (OLIVEIRA, 1999, p. 62).

\section{A pesquisa de campo}

Os procedimentos metodológicos para a realização desta pesquisa consideraram a dinâmica e organização do curso em questão - Administração a distância, que é viabilizado, nos 4 Pólos, que dão suporte à operacionalização do curso. O Pólo de Campina Grande é considerado uma amostra representativa do universo dos alunos do curso por ser composto por 5 turmas, que perfazem um total de 150 alunos.

A pesquisa foi executada sob a abordagem quantitativa e qualitativa por conta das análises descritivas, comparativas e interpretativas, que estão comprometidas com o caráter social da pesquisa, "construção da ciência é um fenômeno social por excelência” (LÜDKE; ANDRÉ, 1986, p. 19).

Com o objetivo de analisar o Ambiente Virtual de Aprendizagem, enquanto plataformas integradoras de ferramentas tecnológicas e pedagógicas, propiciadora de aprendizagem, dando destaque às interfaces tecnológicas interativas, aplicamos, num primeiro momento, um questionário que versava sobre a contextualização do sujeito e sua relação com o ambiente de aprendizagem; sobre a relação de interatividade permitida pelas ferramentas. Em seguida, uma entrevista estruturada com o objetivo de aprofundar algumas idéias não esclarecidas pelo questionário. Das dez questões do questionário, discutiremos apenas duas, face sua importância para a temática que ora discutimos.

Para a primeira questão: que ferramenta(s) disponível no AVA para resolução das atividades permite maior interatividade? Observamos que todas as ferramentas listadas foram consideradas pelos alunos, como interativas. Todavia, o Fórum foi assinalado por $69,2 \%$ 
dos alunos como a ferramenta que permite maior interatividade. Tarefa foi indicada por $41,0 \%$ dos alunos. Chat por $38,5 \%$ deles, e Questionário, 20,5\% dos alunos indicou também como uma ferramenta que permite maior interatividade.

Diante desse resultado, foi necessário saber dos alunos o que eles entendiam por interatividade, e porque eles consideraram determinadas ferramentas como interativas, haja vista todas as ferramentas terem sido apontadas como interativas. Para Fórum, justificaram que ela permite maior interatividade porque:

a) Pode-se obter respostas do professor, trocar idéias com outros alunos e promove o debate;

b) Permite a construção do conhecimento;

c) Ela dá vez ao aluno para opinar e ver a opinião dos outros, permite a troca de experiência;

d) Permite o feedback;

e) Permite a comunicação entre professor e aluno.

O Chat foi a ferramenta que recebeu o comentário de que a interatividade acontece pela possibilidade da comunicação síncrona, em tempo real, e por ser uma ferramenta dinâmica.

Já com relação às ferramentas Tarefa e Questionário, as justificativas elegem o feedback com as notas e comentários do tutor como principais fatores que contribuem para a interatividade. No entanto, uma aluna chama a atenção para a forma como as ferramentas - Questionário e Tarefa - são apresentadas: de forma coercitiva temos que usar por conta da avaliação, mas pela interatividade são gostosas.

Quanto ao que os alunos entendem por interatividade, eles foram claros em suas ponderações e entendem por interatividade 
o ato de comunicação entre pessoas, mesmo quando se valiam de outras expressões como: troca de informação, ação desenvolvida entre duas pessoas, contato entre pessoas, troca de experiência, troca de conhecimentos, interação entre pessoas.

Segunda questão: das disciplinas oferecidas, nos dois últimos semestres, que utilizaram ferramentas e que favoreceram a aprendizagem na opinião dos alunos foram: Informática Básica II com 71,8\%, Informática Básica I com 51,3\% e Sistema de Informação com $53,8 \%$. As demais disciplinas apresentaram percentuais abaixo de $36 \%$.

Para esta questão, quisemos saber, por meio da entrevista porque estas disciplinas foram consideradas como as que ofereceram ferramentas que melhor contribuíram para aprendizagem. As justificativas variam também. Para Informática I e II, as disciplinas mais representativas, para eles, como que as mais ofereceram ferramentas que contribuíram para a aprendizagem, o diferencial foi a disponibilidade de vídeo aula, áudio, este último como possibilidade de ser ouvido em MP3 em qualquer lugar, os slides, os testes rápidos, os fóruns da disciplina. Destaque para outro depoimento que diz que essas disciplinas estiveram mais próximas deles.

As demais disciplinas foram destacadas com menor freqüência, mas justificadas como as que apresentaram ferramentas que melhor contribuíram para a aprendizagem deles, pelo fato de utilizarem como estratégias metodológicas algumas atividades pedagógicas como o Seminário, que promove o encontro entre os alunos na elaboração e defesa dos trabalhos; pelos slides. Destacamos que alguns alunos elegeram disciplinas por acreditarem que quando se tem familiaridade com a disciplina, há uma efetiva contribuição para a aprendizagem.

Merece nossa atenção o fato de algumas disciplinas oferecerem atividades com feedback ser considerado como pelos alunos ponto positivo para sua melhor aprendizagem. 
Diante dessas considerações, observamos que a pesquisa resulta no fato de alunos não terem consciência da importância das ferramentas tecnológicas para a construção da aprendizagem colaborativa.

Se para Silva (2006) e Belloni (2006), interatividade são mecanismos que potencializam o diálogo entre as partes com vistas à intervenção, o diálogo para uma construção coletiva do conhecimento, para os alunos do Curso de Administração a Distância a idéia de interatividade ainda não está muito clara, conforme observamos na pesquisa.

No entanto, esses alunos reconhecem as disciplina que investem nos recursos tecnológicos como forma de promover a interatividade e interação, razão pela qual eles atribuírem serem ferramentas interativas, aquelas que promovem a comunicação.

Portanto, para esses alunos a possibilidade do debate, do diálogo, da intervenção enquanto ações que promovem a reelaboração do conhecimento, ainda estão distantes do seu cotidiano acadêmico.

\section{Considerações finais}

Para uma educação de qualidade, seja a distância ou presencial, propomos uma educação que efetivamente tenha o foco voltado para a aprendizagem. E, em especial para a modalidade a distância que sua organização esteja centrada na modelagem do ambiente, na mediação pedagógica e no planejamento de atividades pautadas na reelaboração do significado com investimento em ações que valorizem a interatividade permitida pelos dispositivos tecnológicos.

Todavia, o papel do professor éfundamental nesse processo, pois ele é responsável pelo planejamento de atividades que promovam 
no aluno o pensamento crítico. É responsável por estimulá-los quanto à progressão dos estudos, pela promoção da maturidade e autonomia, aspectos necessários para que o aluno possa intervir em prol de uma melhor e maior participação na sociedade.

Operacionalmente, muitas dessas situações podem ser efetivadas com uma gerência comprometida com a concepção sóciointeracionista. O Ambiente Virtual - Moodle - já foi programado para essa possibilidade, mas ele não opera se não têm pessoas-professores por trás que tenham essa definição pedagógica.

Por tudo isso, concluímos este trabalho na perspectiva de que os cursos a distância considerem a possibilidade de viabilizar a disseminação da cultura sóciointeracionista, sobretudo, junto aos alunos, de forma que eles compreendam com a própria vivência o que significa uma ação interacionista, e assim possam intervir para melhor qualidade do seu curso.

Todavia, evidenciamos que esta discussão não se esgota com este trabalho. Há a pretensão de continuar os estudos, investigando outros atores desse processo, especificamente, os professoresformadores que têm papel fundamental nessa história, mas que também possuem limitações.

\section{Referências}

ASSMANN, H. (Org.). Redes digitais e metamorfose do aprender. Petrópolis: Vozes, 2005.

BELLONI, M. L. Educação a distância. Campinas, SP: Autores Associados, 2006.

BOGDAN, R.; BIKLEN, S. Investigação qualitativa em educação.

Porto: Porto, 1994. 
CHIZZOTTI, A. Pesquisa em ciências humanas e sociais. 4. ed. São Paulo: Cortez, 2000.

COLAÇO, V. de F. R. Processos Interacionais e a Construção de Conhecimento e Subjetividade de Crianças. 2004. Disponível em: $<$ http://redalyc. uaemex.mx/redalyc/pdf/188/18817306.pdf $>$. Acesso em: 2 out. 2007.

FerreirA, A. B. de H. Novo Dicionário da Língua Portuguesa. 2. ed. Rio de Janeiro: Nova Fronteira, 1986.

FERREIRA, S. de L.; BIANCHETTI, L. As tecnologias da informação e da comunicação e as possibilidades de interatividade para a educação. Revista da FAEEBA, Salvador: UNEB, v. 13, n. 22, p. 253-263, 2004. Disponível em: <http://www.revistadafaeeba.uneb.br/anteriores/ numero22.pdf >. Acesso em: 15 abr. 2008.

FIORENTINI, L. M. R; MORAES, R. de A. (Orgs.). Linguagens e Interatividade na Educação a Distância. Rio de Janeiro: DP\&A, 2003.

GIL, A. C. Como elaborar projetos de pesquisa. 4. ed. São Paulo: Atlas, 2007.

KOCH, I. G. V. Desvendando os segredos do texto. São Paulo: Cortez, 2002.

KENSKI, M. V. Educação e tecnologias: o novo ritmo da informação. Campinas, SP: Papirus, 2007.

LÉVY, P. Cibercultura. 2. ed. São Paulo: Editora 34, 2000.

LUDKÉ, M.; ANDRÉ, M. E. D. A. Pesquisa em educação: abordagens qualitativas. São Paulo: Editora Pedagógica e Universitária, 1986.

MACHADO, A. Pré-cinemas \& pós-cinemas. Campinas,SP: Papirus, 1997. 
MORAN, J. M.; MASETTO, M. T.; BEHRENS, M. A. Novas tecnologias e a mediação pedagógica. Campinas, SP: Papirus, 2000.

. O que é Educação a distância. 2002. Disponível em: <http:// www.eca.usp. br/prof/moran/dis.htm>. Acesso em: 18 jun. 2008.

MUZINATTI, C. M. A. Mundo moodle: conhecimento em construção. 2005. Disponível em: <http://cidade.usp.br/redemoinhos/?2005-03/ fundamental>. Acesso em: 4 mai. 2008.

OLIVEIRA, M. K. de. Vygotsky: aprendizado e desenvolvimento, um processo sócio-histórico. 4. ed. São Paulo: Scipione, 1999.

Pensar a educação contribuições de Vygotsky. In: CASTORINA, J. A. et al. Piaget-Vygotsky: novas contribuições para o debate. 6. ed. São Paulo: Ática, 2003.

PEREIRA, E, W. Educação a distância: concepção e desenvolvimento. 2003. Disponível em: <http://www.fe.unb.br/linhascriticas/n17/ educacao_a_distancia.

html>. Acesso em: 2 out. 2007.

PRIMO, A. Ferramentas de interação na web: travestindo o ensino tradicional ou potencializando a educação através da cooperação? Disponível: <http://www.c5. cl/ieinvestiga/actas/ribie2000/papers/210/index.htm >. Acesso em: 18 mai. 2008.

PULINO FILHO, A. R. P. Moodle: Um sistema de gerenciamento de cursos. Brasília: Universidade de Brasília, Departamento de Engenharia Civil e Ambiental. 2005. Disponível em: <http://www.aprender.unb.br/>. Acesso em: 8 abr. 2008.

RICHARDSON, R. J. et al. Pesquisa social: métodos e técnicas. 3. ed. São Paulo: Atlas, 1999.

SILVA, M. (Org.). Educação online. São Paulo: Loyola, 2003. 
Sala de aula interativa. 4. ed. Rio de Janeiro: Quartet, 2006.

UNIVERSIDADE ESTADUAL DA PARAÍBA. Coordenação Institucional de Programas Especiais - CIPE. Projeto do Curso de Administração a Distância. Campina Grande: UEPB, 2005.

VAN DER LINDEN, M. M. G. Diálogo didático mediado on-line: subsídios para sua avaliação em situações de ensino-aprendizagem. 2005. 261f. Tese (Doutorado em Engenharia de Produção) - Universidade Federal de Santa Catarina, Florianópolis, 2005

VYGOTSKY, L. S. Pensamento e linguagem. São Paulo: Martins Fontes, 1988.

. A formação social da mente: o desenvolvimento dos processos psicológicos superiores. São Paulo: Martins Fontes, 1998. 